\title{
Educational research and training innovation in cardiothoracic surgery: A year in review
}

Megan F. Hunt, BS, Xun Zhou, MD, Cecillia Lui, MD, and Stephen C. Yang, MD

\footnotetext{
From the Division of Thoracic Surgery, Department of Surgery, The Johns Hopkins Medical Institutions, Baltimore, Md.

Disclosures: Authors have nothing to disclose with regard to commercial support.

Received for publication Oct 3, 2018; revisions received Dec 5, 2018; accepted for publication Dec 6, 2018; available ahead of print Jan 23, 2019.

Address for reprints: Megan F. Hunt, BS, The Johns Hopkins Medical Institutions, 600 N. Wolfe St, Blalock 240 , Baltimore, MD 21287 (E-mail: mhunt25@jhmi.edu).

J Thorac Cardiovasc Surg 2019;157:1722-7

$0022-5223 / \$ 36.00$

Copyright (c) 2018 by The American Association for Thoracic Surgery

https://doi.org/10.1016/j.jtcvs.2018.12.020
}

Education within the field of cardiothoracic (CT) surgery is overwhelmingly important to the future of this specialty. With more than 800 sessions across the 2017 to 2018 CT surgery annual meetings (American Association for Thoracic Surgery [AATS], European Association for Cardio-Thoracic Surgery, European Society of Thoracic Surgeons, Society of Thoracic Surgeons [STS], Southern Thoracic Surgical Association, and Western Thoracic Surgical Association), it has been an exciting year for the field. However, this volume of research renders it difficult to keep abreast with the latest innovations in education. This year alone in CT surgery, there were 35 education-focused abstracts, 24 sessions oriented toward emerging technology, and more than 180 sessions devoted to surgical skills and simulations. Many studies explored the role of technology-based tools in augmenting CT surgery training. These were applied to the field broadly, within subspecialties, and at all levels of medical training from medical student to senior attending. Research also grappled with how to best enhance recruitment of students into CT surgery. It is these advances in education that will prove vital to the future of CT surgery education.

Reflecting on the extensive scholarly work published and presented at the major CT surgical conferences, the aim of this paper is to explore the education highlights of the 2017 to 2018 academic year and provide commentary on where the field may be headed.

\section{EDUCATIONAL RESEARCH ACROSS THE FIELD OF CT SURGERY \\ Structure of the Field}

Many researchers over the course of the year investigate how the field of CT surgery is changing and how trainees in particular are responding. The presence of physician extenders within CT surgery has increased in recent years. A national survey assessing opinions of physician extender involvement showed that overall impression is favorable but

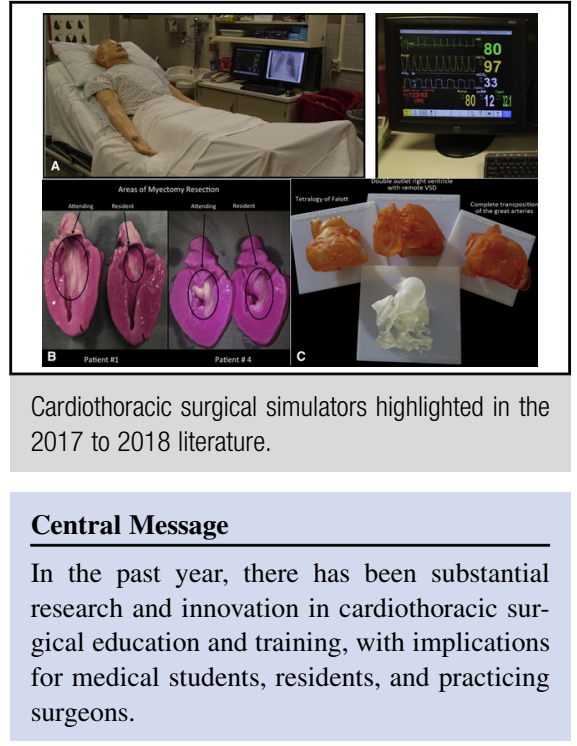

that their role can occasionally impede resident education, especially in regard to patient management on the ward. In regard to training structure, residents appear to prefer traditional programs to the integrated 6-year (I-6) program. The most common reasons given for not applying to the I-6 program were lack of commitment to CT surgery as a medical student and uncertainty of adequacy of I-6 training - from the belief that general surgery training is more well-rounded. ${ }^{2}$ For general thoracic surgery, the $4 / 3$ and traditional programs were the preferred and more common route compared with the I- 6 residents, who nearly all were set on a cardiac career (adult or congenital)., ${ }^{2,3}$ I-6 programs also increase concern about decreased general surgery operative volume, which emphasizes the need for cooperation and communication between integrated and categorical program directors to ensure adequate training for all residents. ${ }^{4}$ Understanding the advantages and challenges of the various educational paradigms, programs continue to modify and improve their curriculum to better address the perceived needs of the specialty and those of the trainees.

\section{Support for Residents' Transition to Training and to Practice}

Research this year focused on understanding how to better support CT surgery residents. Throughout the conferences this year, many sessions were oriented toward 
career planning for residents. The STS Residents Symposium focused on transitioning from residency to a successful practice. At AATS, there was a session entitled "Survival Guide: Your First Night on Call" and a Cardiothoracic Careers College-an 8-hour session devoted to important career decisions for any resident, but especially those interested in CT surgery. Yet, in a survey concerning the experience of first-job seeking CT surgeons, the results emphasized the limited guidance in the field for those securing first employment, despite the length and rigor of residency. ${ }^{5}$ Residents do not feel well-supported in this regard due to a lack of individually tailored resources. With the projected shortage of CT surgeons by 2030, organizations and residency programs should pioneer programs to assist in the hiring process, if not integrate them into the yearly meetings.

\section{Mentorship Research}

Research in the field of medical education continues to highlight the important role that mentorship plays in training. In total, $91 \%$ of residents agreed that mentorship is critical to success, but many found that the characteristics they sought in a mentor changed during training. ${ }^{6,7}$ Residents reported that mentorship was lacking in the areas of work-life balance, job assistance, and career advice. ${ }^{6}$ Results showed sex differences in mentor qualities sought; men reported mentors were more impactful in teaching technical skills and clinical ability, whereas women valued mentors as role models who assist with networking. ${ }^{6}$ However, women in CT surgery, in particular, feel there is a lack of exposure to same-sex mentors at their own institution. Social media could be used to enhance same-sex mentorship across institutions. ${ }^{8}$

Early mentorship for medical students has proven to be important in recruitment into CT surgery. Effective strategies have ranged from establishment of a Cardiothoracic Surgery Interest Group, summer scholar programs, mentoring programs for first-year medical students, and hands-on interactive workshops. In establishing a Cardiothoracic Surgery Interest Group program, student responses showed that preset events with early exposure to CT surgery via shadowing and stress-free interaction with faculty could increase preclinical interest in the field. ${ }^{9}$ Their results also emphasized that more advocacy is necessary to clear up misconceptions about a career in CT surgery. ${ }^{9}$ The Summer Scholars program increased recruitment into the field; of 16 students in the program, 7 matched into surgical specialties with 5 in CT surgery. ${ }^{10}$ For 37 medical students in an early mentorship program, $24 \%$ went into CT surgery and $5 \%$ are pursuing a career in academic surgery. Interactive workshops with high tutor to student ratios resulted in a $42 \%$ increase in perceived attraction to the CT specialty following these workshops. ${ }^{11}$ These success programs were all particularly motivated by the decreasing applicant pool and projected shortage of CT surgeons. Thus, the result of greater rates of CT trainees as a product of increased interest is particularly promising for the future of CT surgery.

Despite increased recruitment, however, baseline interest in CT surgery is low for female medical students. ${ }^{12}$ However, their work suggested greater interest could result if residency programs addressed lifestyle concerns, priorities of family planning, and issues of health disparities. Thus, efforts should be made to address these factors in the recruitment of female medical students.

Opportunities for medical students and general surgery residents interested in a CT surgical career is at an unprecedented and all-time high, due to the generous support of all the national professional organizations and their leadership. Recognition for outstanding research by CT surgery fellows in training is awarded at all the meetings. These activities, offered to nearly 250 students and trainees, include support for travel to meetings, opportunity to research with a mentor, or recognition for excellence in research (Table 1). Attendance at meetings remains the most invaluable experience students and residents use for mentorship and exposure to the wide breath of CT surgical experience. The AATS, STS, Southern Thoracic Surgical Association, and Women in Thoracic Surgery provide travel support and mentorship to their respective annual meetings, totaling more than 100 students and residents. The Thoracic Surgery Directors Association sponsored the 10th Annual Boot Camp in Simulation to 40 CT surgery residents from around the United States. ${ }^{13}$ This annual event remains popular for both trainees and the over 50 faculty who volunteer their time and efforts to this educational activity.

\section{Simulation}

Across the subspecialties of CT surgery, the use of simulation to augment CT surgery education has been drastically increasing. The broad results show that simulation is a useful tool to assist in skill acquisition. In using a technologyenhanced simulation (Figure 1, $A)^{14-16}$ for both integrated and traditional residents transitioning into CT training, residents showed objective improvement in providing the specialized care of CT patients and felt more confident following the training modules. ${ }^{14}$ In addition, an extensive simulation-based curriculum for CT trainees showed improved confidence and also increased examination pass rates over the 3 -year period. ${ }^{17}$ Although most simulation research focused on individual skill acquisition, a team simulation approach with CT residents acting as surgeons, anesthesiologists, perfusionists, surgical assistants, and operating room technicians was shown to successfully model real-world scenarios in cardiac surgery and augment resident training. ${ }^{18}$ Simulations like these that repeatedly show an increase in confidence and aptitude could ultimately improve patient safety when residents transition into CT training. Thus, researchers should be encouraged 
TABLE 1. Available research, mentorship, and travel awards to medical students and residents by national organizations

\begin{tabular}{|c|c|}
\hline Organization & Available opportunities and awards \\
\hline American Association for Thoracic Surgery (AATS) & Member for a Day; Medical Student Summer Interns Awards \\
\hline European Association for Cardio-Thoracic Surgery (EACTS) & Young Investigator's Award; Academy Travel Award \\
\hline European Society of Thoracic Surgeons (ESTS) & Young Investigator's Award \\
\hline General Thoracic Surgical Club (GTSC) & Peter Pairolero Resident Scholarship Award \\
\hline Society of Thoracic Surgeons (STS) & $\begin{array}{l}\text { Looking to the Future Travel Award for medical students and residents; CT } \\
\text { Residents Jeopardy Competition for North America; CT Surgery in the Future } \\
\text { (medical student program at the American College of Surgeons Annual meeting) }\end{array}$ \\
\hline Southern Thoracic Surgical Association (STSA) & $\begin{array}{l}\text { James Brooks Scholarship Award for medical students and residents; Hawley Seiler } \\
\text { Resident Award for Research }\end{array}$ \\
\hline Thoracic Surgery Directors Association (TSDA) & Benson Wilcox Award for best resident paper at STS; Resident Travel Award \\
\hline Thoracic Surgery Foundation (TSF) & Resident Research Award; TSF-STSA Resident Research Fellowship \\
\hline Thoracic Surgery Residents Association (TSRA) & Annual "Boot Camp" in Simulation; Traveling Fellowship Award (with STS) \\
\hline Women in Thoracic Surgery (WTS) & $\begin{array}{l}\text { A.J. Carpenter Traveling Fellowship; Carolyn Reed Traveling Fellowship Award; } \\
\text { Scanlan/WTS Traveling Mentorship Award; WTS Scholarship Program }\end{array}$ \\
\hline Western Thoracic Surgical Association (WTSA) & Traveling Fellowship for Residents and Trainees; Paul C. Samson Resident Prize \\
\hline
\end{tabular}

CT, Cardiothoracic.

to continue developing programs that aid in resident and surgeon education.

\section{EDUCATIONAL RESEARCH SPECIFIC TO SURGICAL SUBSPECIALTY \\ Cardiac}

Research within cardiac surgery addressed how simulation can be used to improve surgical technique and patient care. Several studies assess the role of simulation in planning and training of specific surgical techniques, like thoracic endovascular aortic repair, minimally invasive cardiac surgery (MICS), and septal myotomy. For thoracic endovascular aortic repair, a simulator was created that enables patient-specific rehearsal using 3dimensional (3D) models generated from computed tomography data. Patient-specific rehearsal before actual procedures was found to be feasible and realistic but requires improvements in validity and cost to foster implementation in practice. ${ }^{19}$ A hands-on education MICS program for surgeons that have completed residency was developed based on the Kirkpatrick Four-Level Training Evaluation Model to capture both qualitative and quantitative data about learning, skill acquisition, and program reactions. The overall program implementation fidelity was gauged using interviews and debrief sessions. The study identified that hands-on sessions covered an important gap in MICS teaching. Based on pre- and postsurvey data, the MICS program improved confidence and average preparedness in participants. ${ }^{20} \mathrm{~A}$ 3D-printing-based simulator of septal myotomy was created to teach septal myotomy to residents. This model received favorable feedback and demonstrated improvement in resident skills, with much benefit garnered from the ability to operate on different patient-specific model hearts (Figure 1, B). ${ }^{15}$ The institution of simulators that provide patient-specific rehearsal opportunities have shown great potential within the field of cardiac surgery.

Much work was been done this year in discovering the best methodologies for using existing simulators in training residents and surgeons. The outcomes of these studies vary with greater time devoted to simulation training as an important indicator of success. Vanderbilt University Medical Center instituted a novel simulation curriculum with didactic sessions and low- and highfidelity simulators of vessel cannulation, cardiopulmonary bypass, and operative procedures, like coronary artery bypass grafting, aortic valve replacement, and ascending aorta replacement for four of their residents. Those in the program endorsed the benefit of this curriculum as facilitating "earlier technical opportunities in the operating room" and greater involvement of cardiac surgery faculty. Those in the 4-week curriculum in particular had a large increase in experience in each of the skills emphasized. $^{21}$ In a different study of simulation curricula, a multicenter prospective randomized trial of a low-fidelity simulation platform of aortic and coronary anastomoses in senior residents and fellows failed to show a significant benefit in skill improvement as assessed by video. However, this lack of benefit was a result of insufficient use of the simulator by those in the simulator arm of curriculum. ${ }^{22}$ The result should reflect less on the impact of simulation on training and more on the specific study design and/or simulator. Though these studies have varying successes in regard to their curricula, both suggest that the more time is spent using a simulator, the more improvement a trainee will have at that skill. 


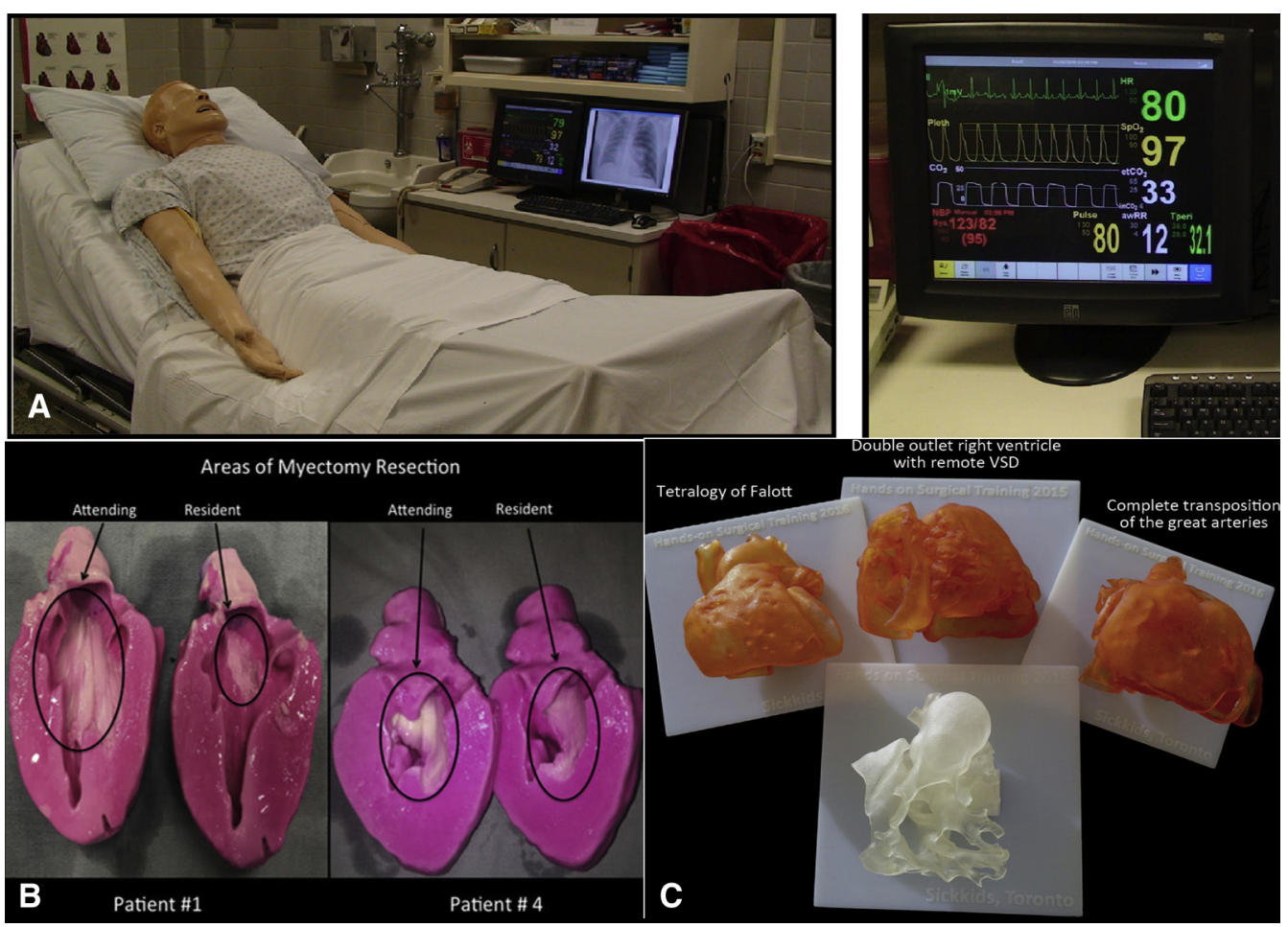

FIGURE 1. Examples of simulation used in cardiothoracic surgical education highlighted in the past year. A, Technology-enhanced mannequin simulator as a component of transition-to-residency curriculum. ${ }^{14} \mathrm{~B}$, printed $3 \mathrm{D}$ models of septal myectomy, with areas of resection highlighted in black circles, comparing myectomy performed by attending and resident at the beginning (left) and near the end of the study (right). ${ }^{15} \mathrm{C}$, Four examples of $3 \mathrm{D}$ models used for congenital cardiac surgical simulation (clockwise from top: double-outlet right ventricle, transposition of the great arteries, hypoplastic left heart, tetralogy of Fallot). ${ }^{16}$ VSD, Ventricular Septal Defect.

\section{Congenital}

Congenital research addressed enhancing surgical preparation for the vast variety of heart defects. With this unique anatomy and multitude of surgeries, creating realistic and representative educational simulators has been a challenge. New 3D-printed models of hearts with congenital heart defects could provide the solution. These hearts can be used to mimic complex congenital cases like arterial switch, Norwood procedure, and repair of double-outlet right ventricle (Figure $1, C) .{ }^{16}$ Questionnaires based-feedback from 50 participants indicated that there is still work to be done on perfecting the model material, but that this type of simulation was beneficial in improving their surgical skills. ${ }^{23} 3 \mathrm{D}$ print-simulation technology is achievable, although still under development. It ultimately has the potential to revolutionize congenital heart surgery education from opportunity-based education to requirement-based standardized education. ${ }^{23}$

\section{Thoracic}

Simulation and curricular technology have also been of great interest in thoracic surgical education in regard to developing novel simulators and to implementing skill training. In the realm of novel technology, the videoassisted thoracoscopic surgery (VATS) assessment tool, an assessment tool for VATS lobectomy in a clinical setting, was developed to train surgeons in this technology and further enhance the safety of minimally invasive thoracic surgery. ${ }^{24,25}$ Validity of VATS assessment tool technology was provided through the unitary framework. A cervical esophagogastric anastomosis simulator (CEGA) was developed for resident training to realistically mimic the CEGA operative site to be repaired via side-to-side staples. ${ }^{26}$ The CEGA simulator is in the early stages of development with necessary improvements, but fidelity scores derived from surveys of 8 faculty who perform CEGA regularly reflected a global observed average of 3.25/4. Thus, the simulator will continue to be developed for future resident training and eventual testing to determine if it improves patient outcomes.

Outside of simulators, curricular models have been studied to determine their effectiveness for both residents and senior surgeons. The use of online preparatory curricula by thoracic surgical trainees affected the results of inservice training examinations. High-volume users with mid-range initial scores had the greatest improvement. ${ }^{27}$ To facilitate the education of more senior surgeons, the 
Italian VATS group developed Very Experienced Time honoUred Surgeons (VETUS), a self-assessment method to facilitate VATS lobectomy skill acquisition. ${ }^{28}$ The VETUS tool provides a training curriculum for senior surgeons to independently and anonymously acquire VATS skills and receive periodic tests to ensure skill enhancement. Their pilot study, involving 100 surgeons in practice for 10 years or more, demonstrated that VETUS displayed internal consistency and participants were compliant to curricular increases of VATS lobectomy use to $30 \%$ to $40 \%$ $(P=.00029)$ after the 1-year curriculum.

Operative autonomy is another topic that was studied in thoracic surgery training. When measuring the autonomy of residents in common operations, both residents and attendings expected the same level of autonomy based on survey responses. ${ }^{29}$ Autonomy was classified on the 4-step scale: "Show and Tell" (1 point), "Active Help," "Passive Help," and "Supervision Only" (4 points). Following cases, residents and attendings rated the autonomy the resident demonstrated during the case on the Zwisch Me!! mobile application. Minor cases were associated with the highest autonomy, followed by thoracic procedures, and then cardiac procedures. Overall, there was a one-"step" rating disparity from the expected (survey-based) autonomy compared to the perceived (Zwisch Me!!-rated) autonomy among senior residents. Thus, an autonomy gap exists between resident and faculty expectations and actual resident autonomy. Although senior residents receive greater levels of autonomy compared with junior residents, they performed only $44 \%$ of operations with significant autonomy. ${ }^{29}$ When looking specifically at female resident autonomy, evaluations showed a significant bias against female residents across seven integrated and traditional thoracic programs. ${ }^{30}$ These autonomy studies indicate that faculty education could aid in fostering autonomy among female residents and help bridge the mismatch in expected and experienced autonomy for all residents.

\section{SUBJECTS IN NEED OF FURTHER RESEARCH Simulator Validity}

Many of the studies cited in this paper are preliminary and derived from abstracts presented at the yearly conferences. These simulators should continue to be enhanced and validated through rigorous study such that this technology can begin to be used to improve operative skill and ultimately patient safety. Further study will allow simulation to move forward and gain widespread acceptance in CT training.

\section{Burnout}

Physician burnout is a serious problem in the medical field. According to MedScape's yearly survey, $42 \%$ of all physicians reported facing burnout. ${ }^{31}$ The role of burnout in CT surgery was addressed in an STS session entitled
"Caregiver Burnout." Squiers and colleagues ${ }^{32}$ discuss burnout further in an Annals of Thoracic Surgery article, noting that $\mathrm{CT}$ surgeons are at increased risk for burnout due to the long duration of residency training, high number of hours worked per week, frequent nights on call, and increasing caseload volumes, but that these factors can be mediated through reduction of stressful stimuli and increased resilience seen as the capacity to handle stress. However, there is an overwhelming paucity of research on burnout rates within CT surgery, leaving a lack of knowledge of who is at risk of burnout, the prevalence of burnout within each subspecialty, and how CT surgeons, specifically, can combat this common trend in medicine. Future research should seek to help elucidate the role of burnout in CT surgery.

\section{CONCLUSIONS}

Although this is not an exhaustive list of topics concerning education in CT surgery, there has been exciting and significant education-based research presented over the course of the major CT meetings in the 2017 to 2018 academic year. Simulation technology, 3D printing, and medical student recruitment were particularly hot topics this year. Mentorship and support for students and trainees interested in CT surgery remain high priorities for all organizations. With researchers instituting the new techniques and programs discussed in this review, it will be exciting to see their impact on the education of future medical students, residents, and faculty. However, there are many lingering questions to be addressed and improvements to be made that could continue to propel CT surgery forward as a field.

\section{References}

1. Blitzer D, Stephens EH, Tchantchaleishvili V, Lou X, Chen P, Pattakos GS, et al. Risks and rewards for the expanding role of physician extenders in cardiothoracic surgery: a national survey. Abstract presented at: Society of Thoracic Surgeons 54th Annual Meeting; January 27-31, 2018; Fort Lauderdale, Fla.

2. Davis TA, Yang SC. Preferences in pathway to becoming a cardiothoracic surgeon: a survey of Current Cardiothoracic Surgery Residents. Abstract presented at: Society of Thoracic Surgeons 54th Annual Meeting; January 27-31, 2018; Fort Lauderdale, Fla.

3. Keilin CA, Sandhu G, Matusko N, Reddy RM. Ten years into the integrated residency era: a majority of thoracic surgeons favor the traditional pathway. Abstract presented at: Western Thoracic Surgical Association 44th Annual Meeting; June 27-30, 2018; Goleta, Calif.

4. Jensen AR, Nickel BL, Dolejs SC, Canal DF, Torbeck L, Choi JN. Impact of integrated programs on general surgery operative volume. Am J Surg. 2017;213: 460-3.

5. Sterbling HM, Molena D, Rao S, Stein SL, Litle VR. Young cardiothoracic surgeons' first job: from searching to securing and the gaps in-between. Abstract presented at: Western Thoracic Surgical Association 44th Annual Meeting; June 27-30, 2018; Goleta, Calif

6. Stephens EH, Goldstone AB, Fiedler AG, Vardas PN, Pattakos GS, Lou X, et al. The current state of mentorship in cardiothoracic surgery training: results of the TSDA/TSRA in-training exam survey. Abstract presented at: Society of Thoracic Surgeons 54th Annual Meeting; January 27-31, 2018; Fort Lauderdale, Fla.

7. Stephens EH, Goldstone AB, Fiedler AG, Vardas PN, Pattakos G, Lou X, et al. Appraisal of mentorship in cardiothoracic surgery training. J Thorac Cardiovasc Surg. 2018;156:2216-23.

8. Luc J, Stamp NL, Antonoff MB. Role of social media in mentorship: a comparative analysis of cardiothoracic surgery and other surgical specialties. Abstract 
presented at: Society of Thoracic Surgeons 54th Annual Meeting; January 27-31, 2018; Fort Lauderdale, Fla.

9. Davis TA, Yesantharao PX, Yang SC. Where do we begin: building blocks to establish a cardiothoracic surgery interest group. Abstract presented at: Society of Thoracic Surgeons 54th Annual Meeting; January 27-31, 2018; Fort Lauderdale, Fla.

10. Moffatt-Bruce SD, Merritt RE, Crestanello JA, Higgins RS, Williams TE. Recruiting the best and brightest medical students into cardiothoracic surgery: a 5-year follow-up. Abstract presented at: Society of Thoracic Surgeons 54th Annual Meeting; January 27-31, 2018; Fort Lauderdale, Fla.

11. George J, Combellack T, Lopez-Marco A, Aslam U, Ahmed Y, Nanjaiah P, et al. Winning hearts and minds: inspiring medical students into cardiothoracic surgery through highly interactive workshops. J Surg Educ. 2017;74:372-6.

12. Foote DC, Meza JM, Sood V, Reddy RM. Assessment of female medical students' interest in careers in cardiothoracic surgery. J Surg Educ. 2017; 74:811-9.

13. TSDA Bootcamp. Thoracic Surgery Directors Association. Available at: http:// www.tsda.org/education/boot-camp/. Accessed October 1, 2018.

14. Chan PG, Schaheen LW, Chan EG, Cook CC, Luketich JD, D'Cunha J. Technology-enhanced simulation improves trainee readiness transitioning to cardiothoracic training. J Surg Educ. 2018;75:1395-402.

15. Hermsen JL, Yang R, Burke TM, Dardas T, Jacobs LM, Verrier ED, et al. Development of a 3-D printing-based cardiac surgical simulation curriculum to teach septal myectomy. J Thorac Cardiovasc Surg. 2018;156:1139-48.e3.

16. Yoo S-J, Spray T, Austin EH III, Yun T-J, van Arsdell GS. Hands-on surgical training of congenital heart surgery using 3-dimensional print models. J Thorac Cardiovasc Surg. 2017;153:1530-40.

17. Moorjani N, Lewis M, Shah R, Barnard S, Graham T, Rathinam S. Implementation of a novel portfolio of structured, curriculum-aligned, simulation-based, cardiothoracic surgery training courses: evolving the delivery of surgical education. J Thorac Cardiovasc Surg. 2017; 154:2009-16.

18. Joyce DL, Lahr BD, Maltais S, Said SM, Stulak JM, Nuttall GA, et al. Integration of simulation components enhances team training in cardiac surgery. $J$ Thorac Cardiovasc Surg. 2018;155:2518-24.e5.

19. Desender LM, Van Herzeele I, Rancic Z, Bicknell C, Zairis I, Vermassen FE, et al. Patient-specific simulation of endovascular thoracic aortic repair: initial experience. Ann Thorac Surg. 2017;104:336-41.

20. Ebunlomo EO, Lazarus MM, MacGillivray TE, Green McClennon CS, Stein KF, Peace BA, et al. Systematic development, implementation, and evaluation of an annual hands-on educational program for minimally invasive cardiac surgery.
Abstract presented at: Society of Thoracic Surgeons 54th Annual Meeting; January 27-31, 2018; Fort Lauderdale, Fla.

21. Archer MA, Nesbitt JC, Michaud NM. Resident perspective of a novel simulation curriculum in cardiac surgery. Abstract presented at: Society of Thoracic Surgeons 54th Annual Meeting; January 27-31, 2018; Fort Lauderdale, Fla.

22. Spratt JR, Brunsvold ME, Joyce D, Nguyen TC, Antonoff MB, Loor GN. Lessons learned from a multicenter prospective randomized study of skill acquisition in cardiovascular surgery using a low-fidelity simulation platform. Abstract presented at: Society of Thoracic Surgeons 54th Annual Meeting; January 27-31, 2018; Fort Lauderdale, Fla.

23. Burkhart HM. Simulation in congenital cardiac surgical education: we have arrived. J Thorac Cardiovasc Surg. 2017;153:1528-9.

24. Jensen K, Petersen RH, Hansen HJ, Walker W, Pedersen JH, Konge L. A nove assessment tool for evaluating competence in video-assisted thoracoscopic surgery lobectomy. Surg Endosc. 2018;32:4173-82.

25. Petersen RH, Gjeraa K, Jensen K, Møller LB, Hansen HJ, Konge L. Assessmen of competence in video assisted thoracoscopic surgery (VATS) lobectomy: a Danish nationwide study. J Thorac Cardiovasc Surg. 2018;156:1717-22.

26. Orringer M, Hennigar DR, Lin J, Rooney DM. Development and initial validation of a cervical esophagogastric anastomosis simulator. Abstract presented at: Society of Thoracic Surgeons 54th Annual Meeting; January 27-31, 2018; Fort Lauderdale, Fla.

27. Antonoff MB, Verrier ED, Allen MS, Aloia L, Baker C, Fann JI, et al. Impact of Moodle-based online curriculum on thoracic surgery in-training examination scores. Ann Thorac Surg. 2016;102:1381-6.

28. Bertolaccini L, Scarci M, Crisci R, Solli P, Rocco G. The very experienced timehonoured surgeons (vetus) method: a self-assessment evaluation for senior surgeons approaching vats lobectomies. Abstract presented at: 26th European Conference on General Thoracic Surgery; May 27-30, 2018; Ljubljana, Slovenia

29. Meyerson SL, Sternbach JM, Zwischenberger JB, Bender EM. Resident autonomy in the operating room: expectations versus reality. Ann Thorac Surg. 2017; 104:1062-8.

30. Meyerson SL, Sternbach JM, Zwischenberger JB, Bender EM. The effect of gender on resident autonomy in the operating room. J Surg Educ. 2017;74: e111-8.

31. Peckham C. Medscape National Physician Burnout \& Depression Report 2018 Available at: https://www.medscape.com/slideshow/2018-lifestyle-burnoutdepression-6009235. Accessed August 28, 2018.

32. Squiers JJ, Lobdell KW, Fann JI, DiMaio JM. Physician burnout: are we treating the symptoms instead of the disease? Ann Thorac Surg. 2017;104:1117-22. 